\title{
O PAPEL DO SISTEMA FINANCEIRO NA AGENDA DE DESENVOLVIMENTO SUSTENTÁVEL E O EXEMPLO DO BANCO DE DESENVOLVIMENTO DE MINAS GERAIS
}

\author{
Sergio Gusmão Suchodolski* \\ Adauto Modesto Júnior ${ }^{* *}$ \\ Adriano Miglio Porto*** \\ Leila Maria Bedeschi Costa****
}

Resumo: O presente artigo nasceu da reflexão sobre o papel do sistema financeiro e de seu braço de fomento, realizada no âmbito das comemorações de 75 anos da Faculdade de Economia e Administração da Universidade de São Paulo - FEA/USP. Naquele contexto, instigou-se a reflexão sobre o papel do sistema financeiro na retomada da economia pós-COVID e da implantação das agendas Globais de Desenvolvimento, em particular o Acordo de Paris e a Agenda 2030. Com base na evolução histórica e nas experiências recentes, argumenta-se que o Sistema Financeiro tem papel central - tanto por dar suporte à atividade econômica tornando-a mais dinâmica quanto por ser capaz de induzir os agentes na direção do modelo de desenvolvimento que se quer, através das condicionantes impostas à concessão de crédito. Portanto, o sistema financeiro - global, regional e local - que no passado recente foi parte do problema, converte-se nesse momento em parte essencial da solução. Dentro desse escopo, bancos regionais de

\footnotetext{
" Presidente do BDMG, diretor do New Development Bank ("Banco do BRICS"), na China. Mestre em Direito pela Harvard Law School, e em Comércio Internacional, Economia e Ciências Políticas, pela Sciences Po-Institut d'Études Politiques de Paris.

** Economista pela USP e mestre em políticas públicas pela Harvard Kennedy School.

*** Economista pela UFMG, mestre em Economia pela UFRJ e doutor em Ciências políticas pela UFMG.

**** Economista pela UFMG, mestre em economia pela UNICAMP e Doutora em Economia pela UFRGS.
} 
fomento se destacam, ao conciliar sua missão histórica - atuação anticíclica, suporte a segmentos estratégicos - com a opção por gerar impacto social e ambiental. Eles exercem papel civilizatório. Trabalham na última milha de uma cadeia que converte finanças líquidas em projetos materiais portadores de futuro no território onde atuam. E isso em razão um maior conhecimento da dinâmica econômica do território e do melhor relacionamento que são capazes de estabelecer com os agentes que nele operam. O artigo foca a evolução do sistema financeiro neste o último século, em articulação aos grandes movimentos da economia mundial em uma síntese sobre seus papéis e, em especial, sobre o dos sistemas financeiros de fomento. Finalmente, os argumentos são ilustrados com a experiência recente do Banco de Desenvolvimento de Minas Gerais - BDMG - cuja missão consiste em ser banco de atuação local, mas também referência global em impacto.

\begin{abstract}
This article was born from a reflection on the role of the financial system and its development arm, carried out within the scope of the 75 th anniversary celebrations of the School of Economics and Administration of the University of São Paulo - FEA/USP. It starts with some considerations regarding the role of the financial system in the recovery of the post-COVID economy and the implementation of the 2030 Agenda. Based on historical evolution and recent experiences, it is argued that the Financial System plays a central role - both in terms of supporting economic activity, making it more dynamic and for being able to induce agents' behavior and decisions towards the desired development model, through the conditions imposed on the granting of credit. Therefore, the financial system - global, regional and local - which in the recent past was part of the problem, now becomes an essential part of the solution. We also argue that regional development banks stand out, by reconciling their historic mission - countercyclical action, support to strategic segments - with the option to generate social and environmental impact. They play a civilizing role, becoming the last mile in a chain that converts liquid finance into material projects that bear the future in the territory where they operate. And this is due to a knowledge of the economic dynamics of the territory and the relationship they can establish with the agents that operate in it. Secondly, the article envisages a synthetic evolution of the financial system since the last century, in articulation with the great movements of the world economy. There follows a summary of their roles and of the development of financial systems. Finally, the arguments are illustrated with the recent experience of the Minas Gerais Development Bank - BDMG - whose mission is to be a local bank and a global reference in impact.
\end{abstract}

Palavras-chave: desenvolvimento - sistema financeiro - SNF - fomento BDMG 
SUCHODOLSKI, S. G. et al. O papel do sistema financeiro na agenda de desenvolvimento...

\section{Introdução}

Abordar o papel do sistema financeiro na construção de uma Nova Era de Desenvolvimento é algo desafiador, mas absolutamente necessário. É sabido que historicamente, crises econômicas tiveram sua origem ou foram intensificadas pelo mau funcionamento do sistema financeiro. Nesse artigo, defende-se a proposição de que o sistema financeiro (global, nacional, local) é essencial e estratégico às economias e no ponto de inflexão no qual a economia internacional se encontra, ele é portador de futuro e tem forte papel civilizatório.

A função clássica do sistema financeiro é prover recursos para dinamizar a economia. E ele o faz mediante a intermediação entre os agentes poupadores e aqueles que necessitam de recursos para manter o giro de seus negócios e/ou viabilizar projetos de investimento. Quando bem regulado e saudável, o sistema financeiro cumpre o papel de acelerar e orientar o crescimento econômico - multiplicando os recursos disponíveis para a construção do futuro através do crédito. Dar crédito significa confiar - contribuir na materialização de expectativas positivas, elementos fundamentais para a decisão de investir, que expande e transforma a economia.

Faz parte da atividade cotidiana do sistema financeiro avaliar a solidez das propostas dos tomadores de crédito. Isso inclui não somente identificar a capacidade de pagamento futuro de quem demanda crédito, mas também avaliar a viabilidade e relevância econômica dos projetos que são apresentados. No processo de concessão, os bancos têm o poder de selecionar os projetos financiados ao incluir pré-requisitos - como em relação à sustentabilidade ambiental e social - que podem direcionar o rumo dos negócios. Precisamente no exercício desta atividade, na escolha das atividades prioritárias a receber mais irrigação de capital através dos financiamentos, as instituições financeiras se constituem em ponte entre o presente e o futuro da economia. Elas são poderosos instrumentos catalizadores para construir o futuro, ao direcionar o capital na sua forma mais líquida (moeda, dinheiro) para "coagulá-lo" ou concretizá-lo na forma de novas redes, empresas, projetos, fábricas, usinas de energia e ainda são capazes de articulá-las ao mesmo tempo com infraestrutura e técnicas de maior produtividade, mais responsáveis e sustentáveis. 
Mais que ferramentas de concessão, análise de crédito e criação de produtos financeiros, são ferramentas de que estas instituições dispõem para induzir o comportamento dos agentes econômicos. Ao destinar um produto financeiro ao empreendedorismo feminino ou negro, ao colocar como requisito a comprovação de economia de energia advinda do projeto, os bancos induzem os agentes na direção de um padrão de produção mais justo e sustentável. Naturalmente a procura tecnológica das empresas nos seus investimentos a serem financiados com capital de empréstimos tende a se dar pelas tecnologias mais de acordo com os projetos incentivados pelos bancos. A evolução tecnológica tende a ser favorecida seguindo as linhas estimuladas ${ }^{1}$. Por exemplo, quando os bancos favorecem a questão da sustentabilidade climática e da descarbonização, tecnologias que apoiem investimentos em geração fotovoltaica têm sua demanda naturalmente estimulada e as que apoiem investimentos em utilização e exploração de carvão mineral são naturalmente desestimuladas.

Embora a política de estímulos e/ou barreiras seja uma escolha que cabe a cada instituição financeira, ela opera dentro de padrões gerais a que todo o sistema financeiro vem sendo induzido, em razão da maior consciência sobre os grandes desafios planetários que se apresentam para a humanidade nesse início de século.

Se consideradas as finanças mundiais e locais como vasos comunicantes, através da regulação internacional e da dinâmica dos mercados financeiros, há que reconhecer que qualquer mudança relevante no padrão mundial do sistema financeiro tem potencial de se propagar e afetar todo o tecido econômico global. E cada agente deste sistema é um elo na propagação dos novos padrões em seu nicho de atuação.

Muitos grupos ao redor do mundo - incluindo o próprio Fórum Econômico Mundial - têm afirmado que o capitalismo precisa ser reiniciado (MAZZUCATO \& JACOBS, 2016). A economia global e a sociedade planetária enfrentam profundos desafios humanitários e climáticos, decorrentes do modelo de desenvolvimento - predatório em relação ao meio ambiente e

${ }^{1}$ Conforme indicam BUAINAIN et ali (2017: 118) "no Brasil, muitas empresas têm encontrado dificuldades para transformar o plano de intenções em favor das inovações numa realidade prática. A falta de acesso a financiamento adequado explica parte desses obstáculos". Para maiores detalhes sobre as relações do sistema de inovação e seu financiamento no Brasil ver este artigo. 
SUCHODOLSKI, S. G. et al. O papel do sistema financeiro na agenda de desenvolvimento...

excludente em relação a grupos humanos. E a esses se somam a crise econômica e sanitária provocada pela pandemia. A economia que existe é a que a sociedade humana foi capaz de construir até agora. Portanto, pode fazer escolhas diferentes daqui para frente. E o sistema financeiro é capaz de jogar seu papel central na necessária transformação desta economia, direcionando a liquidez mundial para materializar um novo projeto de desenvolvimento.

O processo de decisão de financiamento, ao selecionar projetos de investimentos recebedores de recursos, torna-se portador de futuro. Os agentes financeiros podem utilizar seu poder mobilizador de recursos no reforço de um modelo de desenvolvimento predatório, concentrador de renda e desestabilizador das condições de reprodução da vida no planeta. Contudo, alternativamente, o sistema financeiro pode funcionar como ponte para a agenda de desenvolvimento sustentável, impulsionando os ganhos de equidade, sustentabilidade e produtividade que podem pautar uma economia renovada. O posicionamento final do segmento decorrerá dos rumos que a sociedade majoritariamente determinar, o que ocorre, em cada fase da história, pelo processo de regulação, pactuada entre estados nacionais e através de instituições de âmbito internacional. Momentos críticos se verificaram no passado quando a desregulação das finanças mundiais acabou por intensificar e propagar crises advindas do processo produtivo - como no final dos anos 20 do século XX e mais recentemente, em 2007-2008.

A regulação adequada presta-se tanto à estabilidade - e, portanto, funcionalidade do próprio sistema financeiro - quanto ao atendimento de demandas da sociedade humana para uma nova agenda global. E esta mudança já está acontecendo (UNCTAD, 2015; WORLD BANK, 2021). Tanto empresas que se financiam com abertura de capital quanto aquelas que recorrem aos bancos veem-se cada vez mais compelidas a adotar novos padrões de governança e de impactos socioambientais em seus padrões de produção e relacionamento com o mercado. E, nas economias emergentes, a correia de transmissão - entre as diretrizes ASG do mercado internacional e os agentes financeiros locais - tem sido fundamental para acelerar esta transformação. 
Para entender melhor essa potencialidade que ora se coloca, é importante compreender a evolução histórica do sistema financeiro, inserida no processo de desenvolvimento dos mercados e estados-nacionais.

\section{Breve evolução do Estado e do mercado no último século}

Faz-se necessária uma breve lembrança histórica, que nos auxiliará a entender os caminhos trilhados até os problemas do presente, seguida de um rol de desafios que marcarão as próximas décadas.

O último século foi marcado por transformações no modo de vida da humanidade em intensidade e abrangência sem precedentes. Ocorreram mudanças profundas na forma de viver e trabalhar, bem como no uso da ciência e da técnica - que passa a orientar o modo de atuação dos governos, a produção e o consumo. As pessoas também passaram a dispor de mais informações e foram chamadas a participar e influenciar nas escolhas, detendo maiores responsabilidades no palco dos novos arranjos sociais e político-econômicos.

Há cem anos, o mundo ainda estava marcado pelas recentes cicatrizes da Primeira Grande Guerra mundial, pautada pelas disputas imperialistas do século XIX. Na década de 1920, na superação dos impactos da última grande pandemia da "Gripe Espanhola", já se desenhavam sistemas modernos de medicina pública e social. As formas de governo também se modificavam no mundo. Houve a consolidação da Revolução Russa e a maior parte das monarquias existentes foram substituídas em nome da representação popular. Veio a grande depressão no final de 1929 e nos anos de 1930 enfrentou-se a busca de soluções para combater o enorme desemprego e a agitação social. A regulação do Estado foi chamada a elaborar soluções pragmáticas para assegurar o bom funcionamento dos mercados e a prevenir novas crises na economia. Desde o New Deal dos EUA, passando pelos avanços do pacto social, que já se desenhava nos países nórdicos, até a orientação estratégica dos estados ditatoriais do eixo, o Estado passou a garantir melhores retornos aos trabalhadores e a orientar e apoiar a produção.

A Segunda Guerra Mundial - que emergiu ante o aprofundamento da disputa nacionalista e imperialista e durou de 1939 à primeira metade dos anos 1940 - foi poderoso orientador de novas parcerias estratégicas e 
SUCHODOLSKI, S. G. et al. O papel do sistema financeiro na agenda de desenvolvimento...

investimentos entre Estado e setor privado. Acabou escalando a destruição das velhas estruturas utilizando a ciência, com o desenvolvimento de pesquisas e novos produtos e equipamentos através de novas técnicas que permitiram a conquista do espaço e a melhor de transmissão de informações em várias frequências de ondas. A energia atômica se consolidou, com seus potenciais e enormes riscos. O mundo se tornou cada vez mais complexo, com o surgimento de várias novas nações no pós-guerra - já dentro das novas disputas globais entre as áreas de influência do capitalismo e comunismo. As instituições de coordenação mundial se firmaram, sendo cada vez mais necessárias para garantir uma paz capaz de assegurar a sobrevivência da humanidade. Surge a ONU em 1948, apoiando uma aliança mundial para administrar os conflitos no globo e ainda para obter mais qualidade de vida e assegurar direitos humanos a todos na reconstrução necessária.

No plano financeiro e econômico, desde antes do fim da $2^{a}$ Guerra Mundial, novas instituições para a coordenação da economia mundial já estavam sendo desenhadas. A questão de um desenvolvimento mais equilibrado e inclusivo já pautava as discussões que culminam na Conferência Monetária e Financeira das Nações Unidas, realizada em Bretton Woods, em julho de 1944 (BARREIROS, 2009) ${ }^{2}$. Nestes debates, o Brasil participou com uma comitiva de alto nivel ${ }^{3}$ com destaque na atuação

\footnotetext{
2 Ver BARREIROS, Daniel de Pinho. Atuação da Delegação Brasileira na Formulação do Acordo Internacional de Bretton Woods (1942-1944). HISTÓRIA, São Paulo, 28 (2): 2009, pg.515-571.

${ }^{3}$ Segundo Barreiros (2009), "Os principais encontros que antecederam o grande meeting em New Hampshire - a reunião de Washington de 15 de maio a 17 de junho de 1943, e de Atlantic City, entre 26 e 30 de junho de 1944 - contaram com a participação de Austrália, Bélgica, Brasil, Canadá, Chile, Cuba, Tchecoslováquia, Índia, México, Holanda, Filipinas e do Comitê Francês de Libertação Nacional, para além dos Estados Unidos e Reino Unido. O Brasil foi representado por Otávio Gouvea de Bulhões, na ocasião Chefe da Seção de Estudos Econômicos e Financeiros do Ministério da Fazenda e assessor técnico da Comissão de Mobilização Econômica desde janeiro de 1943. Já em Bretton Woods, a comitiva brasileira foi presidida pelo Ministro da Fazenda Arthur da Souza Costa, e teve como delegados Francisco Alves dos Santos Filho (Diretor da Carteira Cambial do Banco do Brasil), Valentim Bouças (da Comissão de Controle dos Acordos de Washington e do Conselho Técnico de Economia e Finanças), o decano das ciências econômicas no Brasil Eugênio Gudin (igualmente do Conselho Técnico de Economia e Finanças e da Comissão de Planejamento Econômico), Vitor Azevedo Bastian (Diretor do Banco da Província do Rio Grande do Sul) e Otávio Gouvea de Bulhões. Além destes, ocupou o cargo de secretário-geral da delegação Aguinaldo Boultreau Fragoso (Assistente do Ministro das Relações Exteriores Oswaldo Aranha), e o cargo de secretário Roberto de Oliveira Campos (na ocasião, segundo secretário da Embaixada do Brasil em Washington), Zeuxis Ferreira Neves (Assistente Técnico do Conselheiro Comercial da Embaixada do Brasil em Washington), Charles Freligh (membro da mesma embaixada), Santiago Fernandes (do Banco do Brasil S.A.), R.R. Vieira (da Delegação do Tesouro Brasileiro em Nova York) e Daniel Maximo Martins."
} 
de Octavio Gouvea de Bulhões, Eugênio Gudin e Roberto Campos como assessores do Ministro da Fazenda, Souza Costa.

$\mathrm{Na}$ visão brasileira acerca da nova ordem financeira internacional em construção, já prevaleciam as estratégias pragmáticas e conciliadoras entre os choques de interesses das propostas do Plano White (norteamericano) e do Plano Keynes (britânico). O Brasil então se pronunciava a favor da criação de instituições reguladoras como o Fundo Monetário Internacional e da pertinência de pontes entres os Planos Keynes e White, considerados complementares em aspectos particulares. Em nenhum momento a delegação brasileira pronunciou-se em favor de qualquer dos planos isoladamente, exercendo uma mediação multilateral que buscava desde então garantir espaço para o Brasil na gestão no aparato econômico institucional mundial criado em Bretton Woods.

O desafio da época no pós-guerra, e que pautou as décadas de 1950 a 1960, era a necessidade da reconstrução com a superação do subdesenvolvimento. Neste contexto foram criados desde a nível mundial a regional uma série de instituições financeiras para ajudar a superar estes desafios: o Banco Mundial (BIRD) em 1944, o BNDE em 1952 (Vargas), o BID em 1959 (sugerido por JK a Eisenhower) e o BDMG em 1962 (também inspirado por JK).

$\mathrm{Na}$ reconstrução e grandes avanços do capitalismo pautado pelo fordismo e keynesianismo nos chamados trinta anos gloriosos do pósguerra até meados da década de 1970, o sistema financeiro exerceu um poderoso papel na dinamização e disseminação do crescimento mundial. Contudo, o mundo se complexificava revelando seus limites nos arranjos social e político que sustentavam o modo de funcionamento das economias centrais e periféricas. Na década de 1970, a experiência do capitalismo "social" e "internacional" passou a sofrer do mal-estar da crise do dólarouro, do primeiro choque do petróleo, da estagflação e do endividamento da periferia alimentado pela reciclagem dos petrodólares. Nesse período, também a geopolítica global ganhava novos contornos com a aproximação China-EUA, ampliando a área de ação do capitalismo, em movimentos de transformação que iriam culminar no colapso da União Soviética em 1989.

A crise financeira no centro do capitalismo foi enfrentada com a enorme elevação dos juros dos EUA promovida pelo Federal Reserve 
SUCHODOLSKI, S. G. et al. O papel do sistema financeiro na agenda de desenvolvimento...

Bank de Volcker, em 1979. A América e boa parte do mundo entraram em recessão, mas o principal banco central do mundo conseguiu domar a inflação de dois dígitos nos Estados Unidos e reinstaurar a soberania do dólar como moeda-reserva. Seguiu-se a crise de divida e da inflação no mundo subdesenvolvido, nos anos 1980, que atingiu particularmente as finanças e o modelo de desenvolvimento do Brasil.

Neste contexto, a complexificação do mundo se aprofundava com a segunda onda de globalização a partir da década de 1980. A desregulamentação financeira, consequente ao novo modelo liberal que se firmava, levou ao crescimento continuado dos fluxos de capitais entre as economias nacionais e o mercado americano. A consequente valorização do dólar intensificou a migração da produção manufatureira para os países de baixo custo da mão de obra (como a China) e a maior concorrência entre as grandes empresas impulsionou uma redistribuição espacial da produção manufatureira, acompanhada de rápida introdução de inovações poupadoras de mão-de-obra. Esse processo veio a reforçar iniciativas locais de catching up que vinham sido levadas adiante por diversos países em desenvolvimento (inclusive o Brasil), desde anos anteriores.

Após a intensificação da industrialização em algumas das economias periféricas, uma relativa estagnação dos rendimentos e crescimento das dividas dos trabalhadores nos países centrais acompanhou a redução da pobreza na periferia. Mesmo com avanços no crescimento, houve a ampliação das desigualdades da renda e da riqueza, com redução nos sistemas progressivos de tributação e o encolhimento da proteção social. Os déficits fiscais se tornaram mais comuns e houve a expansão das dividas dos governos. Nos mercados mais desregulados houve a formação de bolhas sucessivas de valorização dos ativos reais e financeiros apoiada na "alavancagem" financeira.

A enorme expansão dos fluxos de informações e recursos neste capitalismo mais desregulado também aprofundava suas contradições e desafios na transição para o século XXI. Além das desigualdades crescentes, a destruição da natureza e a insegurança mundial avançavam a passos largos. A China passa a se destacar como o novo polo da produção mundial e estimula a demanda pelos recursos globais. O desafio da emergência climática passa a ganhar cada vez mais substância com os alertas dos 
cientistas e os efeitos cada vez mais frequentes de eventos extremos como secas e furacões. O atentado às Torres Gêmeas em 11 de setembro de 2001 mostrou que a escala da guerra e as disputas de ideologias ganhavam novos contornos, indo além de países e envolvendo grupos e organizações mais difusas.

A crise de 2008 - cujo epicentro foi o mercado financeiro - mostrou os limites da economia capitalista de mercados desregulados, atingindo fortemente o país central do sistema. A rápida difusão de seus impactos entre diversas economias nacionais, revelou de forma incisiva a necessidade de um novo reordenamento das finanças, conduzido de forma multilateral e validado pelos estados nacionais.

A segunda década do século XXI já trouxe às finanças o desafio de ajudar na reconstrução do mundo em novas bases, com mais coordenação e parcerias entre o público e o privado, entre o Estado e os mercados. A Conferência da ONU de Adis Abeba em 2015 (UNCTAD, 2015) destacou a enorme necessidade de recursos para a construção da infraestrutura sustentável de que o mundo necessita. Ações coordenadas para superar os desafios climáticos vêm sendo endereçadas desde a conferência de Paris, também ocorrida em 2015. A Pandemia da Covid-19, que fechou esta segunda década, nos demanda cada vez mais coordenação global e bom direcionamento de recursos para a superação da crise.

A terceira década do século XXI assiste a uma enorme transição de modelos e desafios civilizatórios subsequentes que terão profunda influência no modo como a humanidade se relacionará com o planeta nas próximas décadas.

Atualmente, há exemplos concretos de um grupo específico de instituições financeiras - os sistemas de fomento e em seu âmbito, os bancos de desenvolvimento - que já estão atuando na superação desses desafios. Eles ilustram o modo como estas instituições ajudam na necessária transição da economia mundial, ao mesmo tempo que catalisam e aceleram o potencial de desenvolvimento do Brasil e de outros países para construção de um futuro melhor, mais justo e mais sustentável. 
SUCHODOLSKI, S. G. et al. O papel do sistema financeiro na agenda de desenvolvimento...

\section{O desafio da atualidade e o novo papel do Sistema Financeiro}

Em sua capacidade de mobilizar recursos para construção de um novo futuro em bases mais sustentáveis e inclusivas, o Sistema Financeiro se conecta aos desafios contemporâneos. Apesar de ruídos pontuais derivados de um ambiente de radicalização crescente de ideias até com negação da ciência, o mundo e suas principais instituições multilaterais caminham em direção a um sólido consenso sobre a natureza desses desafios e sobre as estratégias para sua superação. Podem ser citados ao menos quatro deles, evidenciados em recentes publicações de organismos multilaterais como Fundo Monetário Internacional (IMF, 2018 e 2019) e agências do Sistema ONU (UNCTAD, 2014, 2015 e 2016)

O primeiro grande desafio diz respeito aos impactos da digitalização sobre uma larga gama de setores e indústrias, movimento que, integrado às mudanças demográficas recentes, terá papel preponderante na dinâmica de crescimento econômico de longo prazo nas principais economias globais. $\mathrm{O}$ crescimento dos ativos digitais e de novas formas de intermediação financeira exercerão pressões sobre o sistema monetário global, alterando de forma significativa o ambiente macrofinanceiro. Isso exigirá uma postura atenta e modernizante dos órgãos reguladores, de modo a garantir a estabilidade dos mercados financeiros. Também abrirá enormes oportunidades de democratização do acesso a serviços financeiros e de transparência da atuação dos atores envolvidos. Passos concretos nessa direção têm sido dados pelo Banco Central brasileiro por meio da agenda $\mathrm{BC}+$, que inclui projetos como o Open banking e o PIX.

O segundo desafio tem a ver com a sustentabilidade e as mudanças climáticas. Até 2030 a humanidade precisará mobilizar entre quatro e sete trilhões de dólares americanos anualmente para implementar os 17 objetivos do desenvolvimento sustentável e suas 169 metas segundo dados da UNCTAD (2014). Além disso, segundo o Painel Intergovernamental de Mudanças Climáticas, as emissões liquidas globais de gases causadores de efeito estufa terão que se reduzir em um terço até 2030 e a zero até 2050 para evitarmos uma trajetória climática de características catastróficas. Nesse campo, o sistema financeiro terá papel central na mobilização e canalização 
dos recursos tanto públicos como privados para projetos alinhados à agenda sustentável, no desenvolvimento de metodologias e taxonomias de classificação dos ativos financeiros em ativos verdes e sustentáveis, na gestão de riscos climáticos e socioambientais dos projetos financiados e na implementação de estratégias de desinvestimentos em setores altamente poluentes e carbono intensivos.

Em terceiro lugar, será preciso enfrentar as desigualdades estruturais - com o desafio de garantir renda e trabalho decente para o conjunto toda a população. Segundo a ONG internacional Oxfam (LUBHY, 2020), em 2018 as 26 pessoas mais ricas do mundo possuiam volume de riquezas equivalente àquele detido pela metade mais pobre da população mundial - ou 3,8 bilhões de pessoas. A literatura econômica recente tem mostrado que além de um problema ético, isso reduz a eficiência econômica (CEPAL, 2018). Somadas à desigualdade de renda, aquelas derivadas das questões de gênero, raça, orientação sexual, religião, regionais e outras prejudicam o crescimento de longo prazo e a confiança nas instituições democráticas, causando instabilidade e incerteza. Esse tema está englobado pelo ODS 8 (crescimento econômico e trabalho decente) do Pacto Global das Nações Unidas e, no Brasil e região, tende a assumir centralidade no debate público brasileiro e latino-americano - principalmente no próximo ciclo eleitoral. O Sistema financeiro tem papel relevante nessa agenda ao ofertar crédito e assistência técnica para empreendedores individuais, micro e pequenas empresas além do desenho de produtos específicos voltados a mulheres, pessoas negras e outros grupos subrepresentados na atividade econômica. Além disso, pode estimular, por meio de condições diferenciadas de crédito a seus clientes, a adoção de práticas laborais decentes e ações de promoção de diversidade e inclusão no interior das empresas. Pode ainda apoiar o setor público na expansão da oferta de bens e serviços à população, não apenas no financiamento direto, mas na elaboração de projetos de qualidade com alto potencial de atração de recursos privados em áreas fundamentais para o desenvolvimento humano, como saneamento básico e iluminação pública.

O quarto desafio se relaciona e condiciona os anteriores e tem a ver com o tema que impactou diretamente a vida humana desde o início de 2020: a pandemia da COVID-19. Num importante relatório publicado recentemente, OPAS, PNUD, UNICEF e UNESCO (PNUD et al., 2021) avaliaram conjuntamente os impactos da crise sobre os indicadores de 
SUCHODOLSKI, S. G. et al. O papel do sistema financeiro na agenda de desenvolvimento...

desenvolvimento humano do país e a vulnerabilidade dos estados brasileiros. Se por um lado, a pandemia exacerbou fragilidades como a desigualdade histórica da sociedade brasileira, por outro, abriu caminho para se repensar o atual modelo e organizar uma recuperação em outras bases, alinhadas com os desafios anteriores. Desafio este compartilhado com outras regiões do planeta (RIAÑO, M. A.; D. BARCHICHE, 2020; BENEDEK, 2021).

Um segmento específico dentro do sistema financeiro se destaca no enfrentamento a estes grandes desafios: o sistema de fomento, composto por uma gama de agentes que vão da atuação global - as agências multilaterais de desenvolvimento - passa por entidades regionais - tais como o Banco Asiático de Investimento e Infraestrutura (AIIB) e o Banco Interamericano de Desenvolvimento (IDB) - até bancos e agências de atuação territorial / local. Diversos países mantêm sistemas nacionais de fomento (SNF), com agentes que atuam em rede com instituições multilaterais e com arranjos próprios quanto ao papel das entidades integrantes.

Cada subsistema nacional de fomento (SNF) tem papel próprio dentro do sistema financeiro nacional, oferecendo crédito direcionado a investimentos de maior prazo de maturação, e consequentemente de maior risco, a segmentos como infraestrutura e inovação, pouco atrativos para bancos exclusivamente comerciais. Além disso, cabe a esse subsistema sustentar a oferta de crédito durante as crises econômicas, quando os agentes financeiros privados tendem a restringir a oferta. Outra sua função típica é corrigir falhas de mercado - fomentando atividades econômicas, setores ou empresas que poderão cumprir papel estratégico no desenvolvimento do país, mas que no momento não estejam nas preferências dos investidores. Finalmente, as entidades públicas do sistema de fomento podem atuar como braços financeiros de seus respectivos governos - contribuindo para racionalizar e multiplicar os recursos fiscais na implementação de suas politicas estratégicas.

Agentes financeiros com mandato para dar suporte a demandas de infraestrutura, inovação tecnológica, práticas sustentáveis, elevação da produtividade agrícola têm surgido inclusive nas nações consideradas comparativamente mais desenvolvidas, como os Estados Unidos da América (SUCHODOLSKI et al, 2021).

O aspecto mais destacado na experiência recente é o reconhecimento 
de que a construção de uma economia mais sustentável e inclusiva depende de soluções desenvolvidas localmente, uma vez que os gargalos se manifestam territorialmente. Pesquisa recente conduzida pela Agência Francesa de Desenvolvimento apontou a profusão de entidades subnacionais que emergiram após 2000, demonstrando a atualidade deste tipo de arranjo para os propósitos de desenvolvimento (SUCHODOLSKI et al, 2021). Temse evidenciado a relevância do SNF para implementação da Agenda $2030^{4}$, com os respectivos Objetivos do Desenvolvimento Sustentável (ODS) e em especial, dos bancos regionais que, pelo fato de estarem imersos nas economias onde atuam, têm mais potencial para identificar situações que potencializem a Agenda (RIAÑO \& BARCHICHE, 2020).

Num processo usualmente chamado "finanças de proximidade", agentes financeiros locais conseguem superar as assimetrias informacionais que pesam sobre os agentes econômicos mais vulneráveis ou inovadores e que consistem em barreiras à obtenção do crédito. Conhecendo as empresas, gestores e a dinâmica das economias nas quais se inserem, esses agentes locais capacitam-se para apoiar processos de reconversão produtiva, desenvolvimento de tecnologias portadoras de futuro ${ }^{5}$ ou investimentos com impactos amplos sobre as cadeias produtivas territoriais. E eles são relevantes pelas razões que seguem.

Primeiramente, enquanto bancos locais, conhecem a dinâmica da economia regional e podem estabelecer relação direta com os agentes

\footnotetext{
${ }^{4}$ Agenda 2030 é um plano de ação global, sintetizado em 17 objetivos de desenvolvimento sustentável e 169 metas, que visa alcançar vida digna a todos, obedecendo as condições e limites do planeta, sem comprometer a qualidade de vida das gerações futuras. O plano foi firmado em 2015 pelos 193 Estado-membros da Organização Das Nações Unidas - ONU, que estabeleceram o compromisso conjunto de buscar alcança-lo até 2030, segundo as medidas / metas recomendadas no documento "Transformando o Nosso Mundo: A Agenda 2030 para o Desenvolvimento Sustentável". Seus objetivos/metas são integrados abrangendo as três dimensões - social, ambiental e econômica - do desenvolvimento sustentável e podem ser colocados em prática por diversos agentes em diferentes níveis desde governos, sociedade civil, setor privado a cada empresa ou cidadão comprometidos com as gerações futuras. Para maior detalhamento ver https://brasil.un.org/pt-br/sdgs.

${ }^{5}$ Alguns centros de pesquisa e empresas do país são capazes de desenvolver novas tecnologias desde novas formas da gestão, ou até mesmo adaptações próprias de modelos exitosos ou estimulados. Sempre há uma imponderabilidade na inventividade de como se dará a construção do futuro, embora obedecendo certas trajetórias que já vão se tornando mais claras. Exemplo: até surgirem alternativas mais claramente econômicas e definidas, o apoio a eficiência do setor sucroalcooleiro num modelo que se baseie em motores híbridos (como eletricidade -álcool) pode ser uma linha interessante para o desenvolvimento energético sustentável no Brasil.
} 
SUCHODOLSKI, S. G. et al. O papel do sistema financeiro na agenda de desenvolvimento...

econômicos que operam no território. E isso é fundamental, uma vez que a própria OCDE (OECD, 2020) constatou que a maior parte dos ODS necessita de parcerias locais para se efetivar ${ }^{6}$. Em segundo lugar, enquanto agentes de desenvolvimento, esses bancos e agências constituem a última milha de uma cadeia de agentes encabeçada pelas agências multilaterais de crédito, operando como elos de um mesmo propósito, possibilitando o acesso aos recursos dessas agências nos projetos locais (LA PORTA, LOPEZDE-SILANES, \& SHLEIFER, 2002; M AZZUCATO \& PENNA, 2016).

No caso brasileiro, os programas governamentais de apoio ao crédito foram fundamentais para minimizar os impactos da recessão produzida pela pandemia $^{7}$. E nesse contexto, um ator cumpriu seu mandato com ênfase: o Sistema Nacional de Fomento brasileiro (SNF), que atuou de maneira anticíclica elevando a oferta de crédito e mantendo em marcha a agenda de desenvolvimento sustentável. E ele continua forte e interconectado. Tendo como instituição central o BNDES (Banco Nacional de Desenvolvimento Econômico e Social), o Brasil conta com 34 instituições, entre bancos comerciais com carteira de desenvolvimento, bancos múltiplos, bancos de desenvolvimento federais e estaduais, agências de fomento, cooperativas de crédito, além da FINEP e do SEBRAE (CUNHA, 2016). Juntas, essas instituições representavam, em 2020, 49\% da carteira total de crédito do país, $75 \%$ do financiamento de longo prazo, 98\% da carteira de crédito ao setor público e $75 \%$ do financiamento a infraestrutura (SUSHODOLSKI et al. 2021).

Além da liderança do BNDES - que atua como banco de segundo piso, dotando todo o sistema de funding para as mais diversas linhas de crédito, o

6 Bancos ao buscarem financiamento externos ao território, conseguem recursos não anteriormente previstos nos orçamentos e que são capazes de ser mobilizados para incentivar investimentos locais, sem pressão fiscal, a não ser que o estado seja chamado, em caso de default, COMO AVALISTA. Desde que os projetos selecionados sejam saudáveis eles podem incentivam a produção, os empregos e a produtividade da região (inclusive do setor exportador) tornando-se capazes de ajudar a gerar os recursos necessários para o pagamento dos empréstimos.

7 Sobre as avaliações e consequências inflacionárias destes programas sugerimos consulta aos documentos do Banco Central do Brasil, desde os que estabeleceram as políticas de estímulo ao crédito aos relatórios periódicos de inflação subsequentes. Contudo, como nos sugere Keynes, no momento da crise o maior prejuízo estaria em não agir. As políticas do controle da inflação, que tendem a avaliar tanto a oferta como demanda agregadas, estão sendo debatidas atualmente. Para maiores informações sobre a dimensão e relevância do sistema nacional de fomento no combate a crise sugerimos consultar a ABDE em https://abde.org.br/ . 
sistema tem coordenação colegiada através da ABDE -Associação Brasileira de Bancos de Desenvolvimento - que estabelece diretrizes conjuntas de atuação e permite o compartilhamento das experiências e pesquisas, fortalecendo o caráter sistêmico da rede de instituições participantes.

O caso do Banco de Desenvolvimento de Minas Gerais, com o modelo que permitiu a forte ampliação de sua atuação nesta crise, exemplifica bem a questão.

\section{BDMG: referência em impacto com atuação local}

Minas é um estado com grandes desafios de desenvolvimento, em razão das enormes disparidades de renda, diferenças climáticas e de distribuição populacional entre suas regiões, mas tem conseguido, através da ação do BDMG, acelerar a implantação da sua agenda de desenvolvimento, em algumas frentes.

Conforme demonstrado no seu último Relatório de Sustentabilidade Anual (BDMG, 2020), o banco vem atuando no suporte à constituição de cidades sustentáveis - infraestrutura com ênfase em redução de emissões, tratamento de resíduos e iluminação com redução de consumo de energia. Este apoio se dá tanto diretamente, como crédito ao ente municipal, quanto através da estruturação de parcerias público-privadas (PPPs) para iluminação púbica ou tratamento de rejeitos. Também o suporte após desastres tem sido objeto de financiamento - como no caso dos municípios atingidos pelos rompimentos em barragens de mineração. Esses apoios vêm ocorrendo não somente através de financiamentos, mas também pelo suporte na estruturação de projetos junto a prefeituras, empresas e setores atingidos.

Desde 2017, o BDMG tem atuado em programas socioeconômicos relacionados à dinamização econômica da região do Rio Doce, nos 35 municípios mineiros atingidos pelo rompimento de barragem da Samarco. Em 2020, os desembolsos totalizaram $\mathrm{R} \$ 27,25$ milhões, crescimento de $31 \%$ em relação ao ano de 2019. No mesmo âmbito, o programa de Coleta e Tratamento de Esgoto e Destinação de Resíduos Sólidos, disponibilizou catorze milhões de reais ( $\mathrm{R} \$ 14$ milhões) em recursos não reembolsáveis, 
SUCHODOLSKI, S. G. et al. O papel do sistema financeiro na agenda de desenvolvimento...

para 25 municípios. Já o Fundo Compete Rio Doce (2018-2020), em parceria com o Sebrae Minas, ofereceu consultoria aos empreendimentos para a reconversão, atendendo 127 empresas e desembolsando $\mathrm{R} \$$ 6,8 milhões.

Uma outra frente de atuação é o apoio à mudança da composição da matriz energética, com o financiamento a parques solares e pequenas centrais hidrelétricas (PCHs). Aqui, o grande potencial mineiro para geração de energia solar, dado seu elevado índice solarimétrico anual, foi valorizado como opção de negócio. Minas Gerais é um estado que sempre se destacou na produção de energia elétrica - sendo sua participação na geração bem superior à sua contribuição ao PIB do país. Além disso, condições geográficas favoráveis e o estímulo à pesquisa de fontes renováveis - liderado pela própria empresa distribuidora estadual - CEMIG - converteram o estado em líder nas duas modalidades renováveis mencionadas. Minas Gerais detém mais de $18 \%$ da capacidade instalada de energia fotovoltaica do país, segundo pesquisa da ABSOLAR (DIÁRIO DO COMÉRCIO, 2021). Com estímulo adequado, o número de sistemas de geração distribuída cresceu exponencialmente desde 2014, superando 36.200 unidades, em 2020. Minas também se destaca também no potencial hídrico e no número de pequenas centrais hidrelétricas, com 65 PCH’s em operação, ante as aproximadamente 400 do pais. Ajudando nesse processo, houve crescimento expressivo das concessões do BDMG em energias renováveis. Em pequenas centrais hidrelétricas, o investimento passou de $R \$ 3,5$ milhões para $\mathrm{R} \$ 10,7$ milhões - crescimento de 206\%. Enquanto em energia solar fotovoltaica foram investidos $\mathrm{R} \$ 54,6$ milhões em 2019 e $\mathrm{R} \$ 87$ milhões em 2020 - crescimento de 60\%.

Uma outra importante vocação mineira - a agricultura (cuja participação no estado também é mais intensa que no paîs) segue objeto de um projeto piloto de sustentabilidade. A atividade agropecuária segue espalhada em todo o território, diversificada entre as regiões e envolvendo diversas culturas. Com graus de produtividade e impacto sobre o meio ambiente bem diferenciados segundo as técnicas adotadas, constitui um desafio e um potencial para o desenvolvimento de Minas. Em parceria com instituições técnicas locais, o banco vem desenhando um projeto que associa crédito e assistência técnica para estimular práticas sustentáveis, o que vem a ser estratégico num contexto de escassez de recursos hídricos e da necessidade de estimular sumidouros de carbono. 
Em 2021, foi assinado um termo de cooperação técnica com a Empresa Brasileira de Pesquisa Agropecuária - Embrapa, instituição que está na vanguarda do desenvolvimento e disseminação de técnicas de agricultura sustentável no Brasil. Também foi firmada parceria com a cooperativa Cresol Minas, que atuará na ponta mais próxima ao cliente final, efetuando a captação das demandas e a análise do crédito. Deverão ser atendidos inicialmente os produtores rurais de portes médio e grande.

A cultura de grãos foi a escolhida - soja, milho, trigo - por apresentar boa aderência à adoção das novas técnicas e ciclo curto, o que agiliza a verificação. Além disso, tem grande relevância para o Estado. Em paralelo às atividades previstas no âmbito da cooperação técnica, durante o projeto piloto o BDMG ofertará linhas de crédito que possam financiar os projetos de transição de uma agricultura convencional para uma agricultura sustentável e de baixo carbono.

Além de iniciativas para captação de novas operações de crédito ou parcerias, o banco também assumiu desde 2020, uma estrutura para certificação da carteira já colocada em termos de seus impactos sociais e ambientais. A construção deste framework de impacto observou os critérios internacionais de finanças sustentáveis, tendo, inclusive, uma Opinião de Segunda Parte ${ }^{8}$ emitida por empresa externa independente. Os atributos de sustentabilidade observados nos créditos já concedidos, por sua vez, funcionarão como parâmetros para a concessão de novos créditos. Desta forma, o banco atua como indutor do comportamento empresarial, fazendo com que o tomador volte seu olhar para o próprio projeto, identificando nele contribuições à redução de emissões e outros beneficios ambientais.

O BDMG ainda concluiu em 2020, em parceria com o BID, o desenvolvimento de uma calculadora de $\mathrm{CO} 2$. Esta ferramenta visa avaliar as emissões, remoções, estoque de carbono florestal e as reduções de emissões das operações financiadas pelo Banco. A calculadora tem sido empregada por diferentes áreas do BDMG para análise de projetos.

Com o objetivo de apoiar as micro e pequenas empresas - MPE's - controladas por mulheres e incentivar o empreendedorismo feminino, o

\footnotetext{
${ }^{8}$ Esta pode ser vista como mais uma auditoria especializada e independente capaz de analisar dentro dos critérios de classificação mais reconhecidos mundialmente as referências usadas para a classificação dos empréstimos que compõe a carteira do BDMG indicados como "verdes", "sociais" e/ou sustentáveis.
} 
SUCHODOLSKI, S. G. et al. O papel do sistema financeiro na agenda de desenvolvimento...

BDMG também disponibiliza a linha de financiamento Empreendedoras de Minas. Por meio dela e da versão "Emergencial", criada exclusivamente para o momento da crise da Covid-19, foram liberados $R \$ 31,2$ milhões em 2020, atendendo a 789 empreendedoras.

A carteira do banco, desde o final de 2020, já refletia a maturidade dessa estratégia de conexão a sustentabilidade, sendo $56 \%$ dos créditos concedidos no ano correspondentes a projetos sustentáveis (alinhados aos ODS), redundando numa carteira 50\% sustentável em 2021. E com base nessa carteira econômica, cada vez mais social e ambientalmente sustentável, que o banco conseguiu emitir externamente cinquenta milhões de dólares (US\$ 50 MM) em títulos sustentáveis em 2020 (BDMG, 2020).

\section{Considerações finais}

O sistema financeiro, que já foi parte do problema - como no aprofundamento das crises dos anos de 1930 e de 2008 - agora é chamado a ser parte relevante da solução para os desafios globais. Não por acaso, a Conferência das Nações Unidas sobre Mudança Climática (COP 26) realizada em novembro de 2021, em Glasgow, tem nas finanças verdes um dos focos das negociações. A contribuição brasileira neste encontro, que contou com representes do sistema nacional de fomento, se deu em torno da busca por consensos e alternativas para o obter o adequado financiamento da transição econômica brasileira e global rumo a um padrão menos carbonointensivo e mais inclusivo.

Durante a COP 26, exemplificando bem o argumento deste artigo, o BDMG oficializou aditivo com o Banco Europeu de Investimento (BEI), em 10/11/2021, num acréscimo de 20 milhões de euros ao limite do contrato original, firmado entre as instituições em $2019^{9}$. Estes recursos adicionais

\footnotetext{
9 No contrato original de 100 milhões de euros, firmado entre as instituições em outubro de 2019, o BDMG captou 100 milhões de euros do BEI, na sua maior operação internacional e na primeira do BEI no Brasil. Inicialmente restrito a iniciativas de energias renováveis e eficiência energética, o contrato teve destinação flexibilizada em novembro de 2020, em função do cenário emergencial deflagrado pela pandemia. $\mathrm{Na}$ ocasião, uma parcela 30\% do total (30 milhões de euros) passou a atender demandas diversas por crédito de micro, pequenas e médias empresas impactadas pela crise sanitária. A extensão do limite sinalizou a confiança do BEI na alocação eficiente de recursos por meio do BDMG, pois em pouco mais de dois anos de parceria, o BDMG endereçou praticamente a totalidade do contrato inicial, somados os valores já desembolsados e os projetos já captados e em análise no banco.
} 
serão utilizados para compor linhas de crédito voltadas ao financiamento de projetos de energias renováveis e eficiência energética no estado de Minas Gerais, além de prover capital para investimentos em micro, pequenas e médias empresas com prazos de até 13 anos, dependendo da natureza da operação e do tipo de negócio, com até dois anos de carência. Este novo acordo também evidencia a importância da parceria com um banco estadual de última milha, com agilidade nos desembolsos, para as prioridades do BEI de impulsionar o desenvolvimento econômico sustentável e inclusivo e fomentar o investimento produtivo na América Latina.

A inserção qualificada do Brasil nesse debate de como financiar a agenda de sustentabilidade e em outros fóruns e instituições multilaterais de desenvolvimento segue fundamental. Necessário reafirmar o protagonismo brasileiro no diálogo ampliado com nações de todos os polos e regiões do globo. No período de 10 anos que se encerrou em 2020, foram dados dois passos muito importantes - a participação do país na fundação do New Development Bank - ou Banco dos Brics - e a recente promulgação do Acordo Constitutivo do Banco Asiático de Investimento e Infraestrutura (AIIB).

Por fim, mais do que nunca o diálogo e a construção de pontes serão elementos fundamentais para que se encontrem soluções e consensos políticos necessários para o avanço consistente na agenda de desenvolvimento sustentável do país, num contexto de democracia e respeito às liberdades e as garantias emanadas da Constituição Cidadã de 88. No âmbito da ABDE, o sistema brasileiro de fomento segue procurando contribuir, dispondo os recursos e capacidade técnica de cada instituição, a serviço do fortalecimento da rede. O desafio maior, do qual o BDMG faz parte, é a formulação de um plano de desenvolvimento capaz de apontar caminhos promissores para superação de importantes gargalos de curto, médio e longo prazos em nossas áreas de atuação. O Fórum Anual do Desenvolvimento, promovido pela $\mathrm{ABDE}$, que ocorrerá no primeiro trimestre de 2022 será também um importante passo nesse processo. 
SUCHODOLSKI, S. G. et al. O papel do sistema financeiro na agenda de desenvolvimento...

\section{Referências}

ABDE. Associação Brasileira de Desenvolvimento. Disponível em: https:// abde.org.br/. Acesso em: 07 dez. 21.

AGÊNCIA MINAS. BDMG assina captação de 20 milhões de euros para Minas Gerais. 10/11/2021. Disponivel em: https://www.agenciaminas. mg.gov.br/noticia/bdmg-assina-captacao-de-20-milhoes-de-euros-paraminas-gerais . Acesso em: 12 nov. 21.

BARREIROS, Daniel de Pinho. Atuação da Delegação Brasileira na Formulação do Acordo Internacional de Bretton Woods (1942-1944). História, São Paulo, 28 (2): 2009, p. 515-571.

BENEDEK, Dora et al. A Post-Pandemic Assessment of the Sustainable Development Goals. IMF. Staff Discussion Notes, v. 2021, n. 003, 2021.

BDMG (Banco de Desenvolvimento de Minas Gerais). Relatório de Sustentabilidade 2020. Disponivel em: https://www.bdmg.mg.gov.br/wpcontent/themes/bdmg/assets-lp/relatorio-de-sustentabilidade .

BUAINAIN, Antônio Márcio; LIMA JUNIOR, Irineu de S.; CORDER, Solange. Desafios do financiamento à inovação no Brasil. Inovação no Brasil: avanços e desafios jurídicos e institucionais. São Paulo: Blucher, p. 97-124, 2017.

CEPAL (Comissão Econômica para a América Latina e o Caribe). A ineficiência da desigualdade. Sintese (LC/SES.37/4), Santiago, 2018.

CUNHA, A. M. PRATES, D. M \& Carvalho, C. E. O Sistema Nacional de Fomento: Formato Atual e Propostas de Reforma. Revista de Análise Econômica 34 (65): 269-300. 2016.

DIÁRIO DO COMÉRCIO. Minas responde por $18,7 \%$ da energia solar no Brasil. 15/10/2021. Disponivel em: https://diariodocomercio.com.br/ economia/mg-responde-por-187-da-energia-solar-no-brasil/. Acesso em: 29 out. 2021.

DUGGAN, Niall; LADINES AZALIA, Juan Carlos; REWIZORSKI, Marek. The structural power of the BRICS (Brazil, Russia, India, China and South Africa) in multilateral development finance: A case study of the New Development 
Bank. International Political Science Review 0-00. 2021.

IMF (International Monetary Fund). Annual report 2018. Building a Shared Future. IFM. Disponivel em: https://www.imf.org/external/pubs/ft/a /2018/. Acesso em: 07 dez. 21.

IMF (International Monetary Fund). Annual Report 2019. Our connected world. IFM: Disponivel em: https://www.imf.org/external/pubs/ft/ ar/2019/. Acesso em: 07/12/21.

LA PORTA, R., F. LOPEZ-DE-SILANES, and A. SHLEIFER. 2002. Government Ownership of Banks. The Journal of Finance 57 (1): 265-301

LUBHY, T. 2019. OXFAM - (Oxford Committe for Famine Relief). The top 26 billionaires own $\$ 1.4$ trillion - as much as 3.8 billion other people. OXFAM: 2020. Disponivel em: https://edition.cnn.com/2019/01/20/ business/oxfam-billionaires-davos/. Acesso em: 07 dez. 21.

MAZZUCATO, M., and C. PENNA. 2016. Beyond Market Failures: The Market Creating and Shaping Roles of State Investment Banks. Journal of Economic Policy Reform 19 (4): 305-326.

OECD (Organization to Economic Cooperation and Development). Progamme on to a territorial approach to SDG's. Report 2020. A role to cities and regions to leave no-one behind. OECD: fev/2020. Disponivel em: https:// www.oecd.org/cfe/territorial-approach-sdgs. Acesso em: 07 dez. 21.

ONU - Objetivos de Desenvolvimento Sustentável no Brasil. Disponível em https://brasil.un.org/pt-br/sdgs. Acesso em: 07 dez. 21.

PNUD (Programa das Nações Unidas para o Desenvolvimento), UNICEF (Fundo das Nações Unidas para a Infância), UNESCO (Organização das Nações Unidas para a Educação, a Ciência e a Cultura) \& OPAS (Organização Pan-Americana da Saúde). COVID-19 e desenvolvimento sustentável: avaliando a crise de olho na recuperação. Brasília, DF; 2021. livro eletrônico. Disponivel em: https://www.unicef.org/brazil/media/16086/file. Acesso em: 07 dez. 21.

RIAÑO, M. A.; D. BARCHICHE. Financing the 2030 Agenda for Sustainable Development: Prerequisites, and Opportunities for the Post-Covid-19 Crisis. 
SUCHODOLSKI, S. G. et al. O papel do sistema financeiro na agenda de desenvolvimento...

IDDRI: Issue Brief. No 3, mai/2020. Disponível em: https://www.iddri.org/ sites/default/files/PDF/Publications/Catalogue. Acesso em: 07 dez. 21.

SCHWAB, Klaus; MALLERET, Thierry. The Great Reset. In: World Economic Forum: Geneva, Switzerland. 2020.

SUCHODOLSKI, S.G.; MODESTO JUNIOR, A.; BECHELAINE, C. H.O. \& Costa, L.M.B. From Global to Local: Subnational Development Banks in the Era of Sustainable Development Goals, Review of Political Economy; Disponivel em: https://doi.org/10.1080/09538259.2021.1977545. Acesso em: 07 dez. 21.

UNCTAD (United Nations Conference on Trade and Development). 2014. World Investment Report 2014: Investing in the SDGs: An Action Plan. United Nations Publication. Disponivel em: https://unctad.org/system/ files/official-document/. Acesso em: 07 dez. 21.

UNCTAD (United Nations Conference on Trade and Development). 2015. AAAA (Addis Ababa Action Agenda) of the Third International Conference on Financing for Development. In: General Assembly - Sixty-ninth session Agenda item 18; Aug.17. 2015. United Nations Publication. Disponivel em: https://unctad.org/system/files/official-document. Acesso em: 07 dez. 21.

UNCTAD (United Nations Conference on Trade and Development). 2016. The Role of Development Banks. In: Promoting Growth and Sustainable Development in the South. United Nations Publication. 2016 (UNCTAD/ GDS/ECIDC/2016/1).

WORLD BANK. Global Economic Prospects. Janeiro, 2021. Disponivel em: https://www.worldbank.org/en/publication/global-economic-prospects. Acesso em: 07 dez. 21. 